\title{
Response of Vitis vinifera cell cultures to Phaeomoniella chlamydospora: changes in phenolic production, oxidative state and expression of defence-related genes
}

\author{
Marta R. M. Lima • Federico Ferreres • \\ Alberto C. P. Dias
}

Accepted: 18 August 2011

(C) KNPV 2011

\begin{abstract}
Cell suspension cultures of Vitis vinifera cv. Vinhão (Vv) were used to study the putative response of $V$ vinifera to Phaeomoniella chlamydospora $(\mathrm{Pc})$, a fungus frequently associated with esca and grapevine decline. Cells were elicited with a Pc autoclaved biomass extract and methyl jasmonate (MeJ). Phenolic production was evaluated by HPLC-DAD and HPLC-MS/MS. Phenolic production of $\mathrm{Vv}$ cells significantly changes after elicitation. Compared to control, Vv cells elicited by Pc extract increase their stilbene production 20 -fold and those elicited by MeJ increase stilbenic production 9-fold. In both cases, there is de novo production of viniferin type compounds. We also analyzed the oxidative burst of $\mathrm{Vv}$ cells after elicitation with Pc extract and MeJ, using the probe 2',7'-dichlorodihydrofluorescein diacetate. Adding Pc extract induces an oxidative burst that shows a biphasic pattern in $\mathrm{Vv}$ cells. Moreover, the induction of 7 defence-related genes expression in $\mathrm{Vv}_{\mathrm{V}}$
\end{abstract}

M. R. M. Lima • A. C. P. Dias (ه)

Department of Biology, CITAB-Centro de Investigação e de Tecnologias Agro-Ambientais e Biológicas,

University of Minho,

Campus de Gualtar,

4710-057 Braga, Portugal

e-mail: acpdias@bio.uminho.pt

F. Ferreres

Research Group on Quality, Safety and Bioactivity of Plant Foods, CEBAS (CSIC),

Campus Universitario Espinardo Edif.,

25, P.O. Box 164, E-30100, Murcia, Spain cell cultures upon Pc extract elicitation was investigated employing semi-quantitative RT-PCR. Elicitation increases the expression of class 6 and class 10 pathogenesis-related proteins, $\beta$-1,3-glucanase, class III chitinase, lipoxygenase, phenylalanine ammonia lyase and stilbene synthase. Therefore, $\mathrm{Vv}$ in vitro cell cultures could be an important tool to study esca disease, since they offer a simple, rapid and selective way to evaluate plant/fungus interactions.

Keywords Cell suspensions - Defence-related genes . Esca disease - Oxidative burst . Phenolic production . Vitis vinifera

\section{Introduction}

Esca is a destructive disease that affects grapevines worldwide. Although esca-like symptoms are reported in ancient Greek and Latin works (Mugnai et al. 1999), only recently has the disease became a major concern due to its dramatic incidence increase. This recent increase has been related to a variety of factors such as changes in the management of vineyards, new cultural practices, introduction of new grapevine cultivars and rootstocks, reduced sanitary care of rootstocks and vineyard propagation material, poor protection of pruning wounds, increasing use of selective fungicides and banishment of arsenite treatment due to its toxicity (Graniti et al. 2000; Surico et al. 2006). Although arsenite treatment did not appear to affect esca-related 